\title{
Hubungan hipertensi terhadap gangguan kognitif pada lanjut usia di Panti Werdha Wana Seraya Denpasar
}

\author{
Rose Vita Sari ${ }^{1 *}$, RA Tuty Kuswardhani ${ }^{2}$, IGP Suka Aryana ${ }^{2}$, Rai Purnami ${ }^{2}$, IB Putrawan ${ }^{2}$, I Nyoman Astika ${ }^{2}$
}

Crossref Crossmark D0I : 10.36216/jpd.v3i1.45
1Program Studi Pendidikan Dokter Spesialis Penyakit Dalam, Fakultas Kedokteran Universitas Udayana/RSUP Sanglah, Denpasar, Bali, Indonesia 2Departemen/ KSM Penyakit Dalam, Fakultas Kedokteran Universitas Udayana/ RSUP Sanglah, Denpasar, Bali, Indonesia

*Korespondensi :

Rose Vita Sari;

Program Studi Pendidikan Dokter Spesialis Penyakit Dalam, Fakultas Kedokteran Universitas Udayana/RSUP Sanglah, Denpasar, Bali, Indonesia Flower_bali@yahoo.co.id
Diterima: 18 Januari 2019; Disetujui: 15 Februari 2019; Diterbitkan: 27 Februari 2019
Latar Belakang: Tingkat kenaikan harapan hidup akan meningkatkan jumlah lansia serta gangguan kognitif. Salah satu risiko akibat hipertensi adalah gangguan kognitif meskipun ada risiko lain. Gangguan fungsi kognitif adalah salah satu komplikasi hipertensi.

Tujuan: Mengetahui korelasi hipertensi terhadap gangguan kognitif di Panti Werdha Wana Seraya Denpasar, Bali. Metode: Studi ini menggunakan analitik observasional dengan pendekatan cross sectional. Subyek dalam studi ini adalah lansia di Panti Werdha Wana Seraya Denpasar. Populasi adalah 46 lansia, dengan sampel 46 lansia yang terlibat dengan cara purposive sampling, diambil sesuai kriteria inklusi. Data dikumpulkan melalui kuesioner MMSE (Mini Mental Status Examination) dan pengukuran tekanan darah. Berdasarkan kriteria MMSE, penurunan kognitif dibagi menjadi dua kategori, dengan gangguan kognitif $(<25)$ dan tanpa gangguan kognitif $(\geq 25)$. Hipertensi dibagi menjadi dua ketegori, hipertensi (systole $\geq 150$ berdasarkan JNC 8 ) dan tidak ada hipertensi $(<150)$. Analisis data menggunakan SPSS 17 denganuji statistic chi-square dan uji korelasi bivariat lamda.

Hasil: Sejumlah 46 sample lansia yang berusia $\geq 60$ tahun mengikuti studi ini. Prevalensi hipertensi dan gangguan kognitif adalah 47\% (22/46) dan 47\% (22/46). Di antara 39\% (18/46) individu yang mengalami hipertensi, gangguan kognitif ditemukan perbedaan yang signifikan $(\mathrm{p}=0,000)$. Ada korelasi yang signifikan antara gangguan kognitif dengan hipertensi jika gangguan kognitif sebagai variable dependen $(r=0,636 ; p=0,001)$.

Simpulan: Terdapat korelasi antara gangguan kognitif dan hipertensi. Hipertensi mempengaruhi fungsi kognitif pada studi ini.

Kata Kunci: hipertensi, gangguan kognitif, lansia, Panti Werdha Wana Seraya Denpasar

Background: The rise degree of life expectation would increase the number of elderly as well as cognitive impairment. One of the risks due to hypertension is cognitive impairment despite of the other risks. Disturbances in cognitive function is one of the complications of hypertension.

Objective: Determine correlation of hypertension to cognitive impairment in elderly in Werdha Wana Seraya nursing home Denpasar, Bali.

Method: This study uses observational analytic with cross sectional approach. Subjects in this study were elderly in Panti Werdha Wana Seraya Denpasar. The population was 46 elderly, with sample of 46 elderly involved by means of purposive sampling, taken according to inclusion criteria. Data was collected through questionaires MMSE (Mini Mental Status Examination) and blood pressure measurements. Based on MMSE criteria, cognitive impairment divided into two categories, with cognitive impairment $(<25)$ and without cognitive impairment $(\geq 25)$. Hypertension divided into two categories, hypertension (sistole $\geq 150$ based on JNC 8 ) and no hypertension $(<150)$. Data were analyzed by chi-square statistical test and Lamda's bivariate correlation test.

Result: All 46 individuals were included (elderly at Panti Werdha Wana Seraya with age $\geq 60)$. The prevalence of hypertension and cognitive impairment were 47\% (22/46) and 47\% (22/46). Among 39\% (18/46) individuals who had hypertension, cognitive impairment was found significantly difference $(p=0.000)$. There was significant correlation between cognitive impairment with hypertension if cognitive impairment as a dependent variable $(r=0.636 ; p=$ $0.001)$.

Conclusion: There is a correlation between hypertension and cognitive impairment. Hypertension affects cognitive function.

Key Words : hypertension, cognitive impairment, elderly, Panti Werdha Wana Seraya Denpasar 


\section{LATAR BELAKANG}

Perkembangan gaya hidup menyebabkan meningkatnya angka kejadian hipertensi di masyarakat. Lima puluh persen lansia (usia $\geq 60$ tahun) menderita hipertensi, hal tersebut memberi kontribusi peningkatan angka kematian lansia per tahun., ${ }^{1,2}$ Data yang diperoleh melalui survei kesehatan rumah tangga (data dari litbang depkes) penderita hipertensi mengalami peningkatan dari tahun 1995 ke tahun 2001, dari 8,3\% menjadi $21 \%$ penderita hipertensi di Indonesia. ${ }^{2}$ Hipertensi yang tidak terkontrol akan menjadi berbagai faktor risiko pada penyakit yang mengancam jiwa seperti stroke dan penyakit kardiovaskuler. Tentunya hal tersebut mengganggu kualitas hidup penderita. ${ }^{3}$

Salah satu komplikasi hipertensi pada sistem saraf pusat selain stroke juga dapat menyebabkan penurunan fungsi kognitif, salah satunya fungsi memori yang bila dibiarkan secara kronis dapat menyebabkan dementia (vascular cognitive impairment). ${ }^{2}$ Beberapa penelitian sebelumnya telah mengungkapkan bahwa hipertensi jangka lama dapat menyebabkan penurunan fungsi kognitif, yang tentunya akan sangat mengganggu kualitas hidup penderita. ${ }^{2}$ Dementia vaskuler merupakan urutan nomor 2 penyebab dementia, dan urutan 1 pada Negara di asia dengan prevalensi sebesar 1,5\% di Negara barat dan 2,2\% di Negara Jepang. Lima puluh persen dementia vaskuler terjadi pada orang dengan usia diatas 65 tahun. Risiko demensia meningkat 9 kali pada pasien stroke $25 \%$ penderita stroke akan mengalami demensia. ${ }^{4}$ Oleh karena itu pada studi ini dicoba mengaitkan meningkatnya kejadian hipertensi yang dapat menyebabkan gangguan fungsi kognitif, maka penulis ingin mengamati efek yang ditimbulkan oleh hipertensi pada fungsi kognitif, sehingga dapat menurunkan insiden dan mencegah gangguan kognitif pada lansia. Studi ini bertujuan untuk melihat hubungan hipertensi dengan gangguan kognitif pada lansia di Panti Werdha Wana Seraya Denpasar, Bali.

\section{METODE}

Studi ini menggunakan analitik observasional dengan pendekatan cross sectional. Subyek dalam penelitian ini adalah lansia di Panti Werdha Wana Seraya Denpasar. Populasi adalah 46 lansia, dengan sampel 46 lansia yang terlibat dengan cara purposive sampling, diambil sesuai kriteria inklusi. Dalam studi ini hipertensi sebagai variabel bebas, gangguan kognitif sebagai variabel terikat dan variabel perancu yaitu diabetes mellitus, riwayat stroke, riwayat gangguan psikiatri. Data dikumpulkan melalui kuesioner MMSE (Mini Mental Status Examination) dan pengukuran tekanan darah. Berdasarkan kriteria MMSE, penurunan kognitif dibagi menjadi dua kategori, dengan gangguan kognitif $(<25)$ dan tanpa gangguan kognitif ( $\geq 25)$. Hipertensi dibagi menjadi dua ketegori, hipertensi (systole $\geq 150$ berdasarkan JNC 8) dan tidak ada hipertensi $(<150)$. Data dianalisis dengan uji statistic chisquare dan uji korelasi bivariat lamda.

\section{HASIL}

Sampel penelitian berjumlah 46 lansia dengan usia $\geq$ 60 tahun. Dari 46 sampel didapatkan 22 individu mengalami hipertensi, begitupula dengan gangguan kognitif didapatkan 22 individu dari 46 sampel. Penelitian dengan menggunakan metode menggunakan analitik observasional dengan pendekatan cross sectional. Dari 46 sampel ditemukan 18 individu (39\%) pasien dengan hipertensi yang juga mengalami gangguan kognitif, setelah dilakukan uji korelasi didapatkan $r=0,636 ; p=0,001$. Ada korelasi yang signifikan antara gangguan kognitif dengan hipertensi jika gangguan kognitif sebagai variable dependen. Pada uji proporsi antara gangguan kognitif dan hipertensi didapatkan $P R=4,87$ dengan nilai $\mathrm{p}$ $=0,001$.

\section{Tabel 1. Demografi Sampel}

\begin{tabular}{|c|c|c|}
\hline Karakteristik Demografi & Total $(\mathrm{N}=46)$ & $\%$ \\
\hline \multicolumn{3}{|l|}{ Jenis Kelamin } \\
\hline Laki-laki & 24 & $52,1 \%$ \\
\hline Perempuan & 22 & $47,8 \%$ \\
\hline \multicolumn{3}{|l|}{ Usia } \\
\hline 60-69 tahun & 10 & $21,7 \%$ \\
\hline$\geq 70$ tahun & 36 & $78,2 \%$ \\
\hline \multicolumn{3}{|l|}{ Tingkat Pendidikan } \\
\hline Tidak sekolah & 6 & $13,04 \%$ \\
\hline SD-SMP & 40 & $86,90 \%$ \\
\hline
\end{tabular}

BMI

$\begin{array}{lll}\text { Malnutrisi } & 12 & 26,08 \% \\ \text { Normal } & 34 & 73,90 \%\end{array}$

Tingkat kemandirian

$\begin{array}{lll}\text { Tergantung } & 14 & 30,4 \%\end{array}$

Mandiri $\quad 32 \quad 69,5 \%$

Hipertensi

$\begin{array}{lll}\text { Ya } & 22 & 48 \%\end{array}$

Tidak $\quad 24 \quad 52 \%$

Karateristik Frailty

Non-frailty $\quad 17 \quad 36,90 \%$
Frailty 29 $63,04 \%$ 
Print ISSN: 2580-2925

Online ISSN: 2580-2933

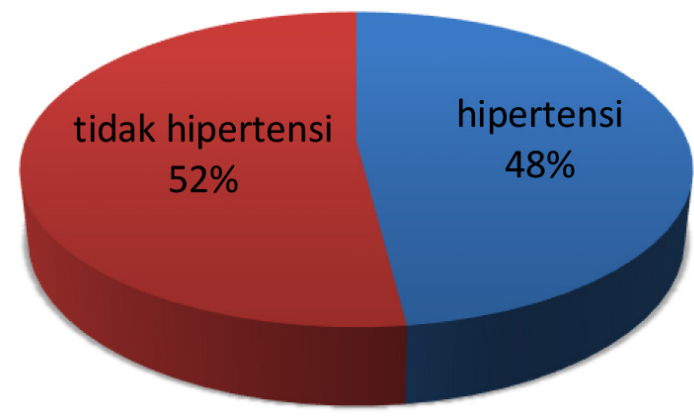

Gambar 1. Distribusi hipertensi di Panti Werdha Wana Seraya Denpasar

Tabel 2. Hubungan hipertensi dengan gangguan kognitif lansia di Panti Sosial Werdha Wana Seraya Denpasar

\begin{tabular}{lccc}
\hline \multirow{2}{*}{ Hipertensi } & \multicolumn{2}{c}{ Gangguan Kognitif } & \multirow{2}{*}{ Nilai P } \\
\cline { 2 - 3 } & Ya & Tidak & \\
\hline Ya & $18(39,1 \%)$ & $4(8,7 \%)$ & \\
Tidak & $4(8,7 \%)$ & $20(43,5 \%)$ & 0.001 \\
Total & $22(48 \%)$ & $24(52 \%)$ & \\
\hline
\end{tabular}

\section{DISKUSI}

Penelitian ini bertujuan untuk mengetahui apakah terdapat hubungan hubungan antara hipertensi dengan fungsi kognitif. Sampel penelitian terdiri dari 46 lansia yang memiliki riwayat hipertensi di Panti Werdha Wana Seraya Denpasar pada bulan Mei 2015. Berdasarkan kriteria MMSE, penurunan kognitif dibagi menjadi dua kategori, dengan gangguan kognitif $(<25)$ dan tanpa gangguan kognitif $(\geq 25)$. Hipertensi dibagi menjadi dua ketegori, hipertensi (systole $\geq 150$ berdasarkan JNC 8) dan tidak ada hipertensi $(<150)$. Hasil dari penelitian ini terdapat korelasi yang signifikan antara gangguan kognitif dengan hipertensi jika gangguan kognitif sebagai variabel dependen $(r=0,636 ; p=0,001)$. Hal tersebut kemungkinan diakibatkan karena pada subjek penelitian yang memiliki riwayat hipertensi lebih dari 5 tahun telah terjadi infark lakuner pada bagian otak tertentu. ${ }^{4,5} \mathrm{Hal}$ ini sesuai dengan studi Kaiser, et al menjabarkan hipertensi dapat mengganggu sirkulasi aliran darah otak yang dapat menyebabkan gangguan fungsi, salah satunya dapat timbul gangguan fungsi kognitif., ${ }^{4,67}$ Komponen fungsi kognitif atensi adalah kemampuan individu dalam kegiatan memusatkan perhatian pada suatu hal dan mengabaikan hal lain yang tidak sedang dipikirkan, dimana atensi ini dikontrol oleh kortek frontal yang berhubungan dengan penglihatan, kemudian pada kortek parietal, dan pada kolikulus superior, dimana bila didapatkan lesi pada regio ini maka akan timbul gangguan fungsi atensi sesuai penelitian yang telah dilakukan oleh Ronald Cohen. ${ }^{8,9}$ Studi Richard pada tahun 2006 dan Cohen tahun 2001, dimana subjek yang memiliki hipertensi esensial cenderung untuk mengalami terjadinya abnormalitas pada susunan saraf pusat, terutama integritas lobus frontalis (kerusakan korteks prefrontal, hiperintensitas substansia alba) yang dibandingkan oleh kelompok kontrol, sehingga didapatkan hasil fungsi kognitif yang lebih buruk.,

Terdapat beberapa penelitian, dimana didapatkan pengukuran variabel lain yang mempengaruhi fungsi kognitif diantaranya adalah pendidikan, merokok, lama riwayat hipertensi. ${ }^{6-11}$ Penelitian yang dilakukan oleh Sunmin pada subjek dengan pendidikan yang tinggi didapatkan hasil fungsi kognitif yang lebih baik dibandingkan subjek dengan riwayat pendidikan rendah, hal ini dikarenakan pada subjek dengan pendidikan tinggi pada awal kehidupannya lebih banyak terbentuk sinaps dan peningkatan vaskularisasi di otak, sehingga kemampuan kognitifnya akan lebih baik, selain itu seseorang dengan riwayat pendidikan akan lebih cenderung untuk mencari edukasi lebih lanjut yang tentunya akan menstimulasi mental dari orang tersebut yang mempengaruhi struktur neurokimiawi otak akibat rangsangan orang tersebut melakukan kerja. ${ }^{7,8,11}$ Pada subjek yang berpendidikan tinggi bila orang tersebut sakit, maka akan lebih cenderung mencari pengobatan pada layanan kesehatan yang baik, sehingga tentunya fungsi kognitif akan lebih baik. ${ }^{12,13}$ Variabel lain yaitu merokok juga mempengaruhi fungsi kognitif hal ini kemungkinan karena rokok menyebabkan gangguan biokimia dalam tubuh terutama pertahanan antioksidan, penurunan perfusi otak, atrofi otak, penipisan substansi putih dan abu di otak, hal tersebut didukung oleh penelitian sebelumnya dimana didapatkan fungsi kognitif yang lebih rendah pada subjek penelitian yang merokok dibandingkan dengan kontrol yang tidak merokok..$^{14,15}$ Lamanya hipertensi juga berpengaruh pada menurunnya fungsi kognitif. ${ }^{8}$ Hal tersebut didukung oleh penelitian sebelumnya dimana pasien yang menderita hipertensi lebih dari 5 tahun dapat berpengaruh pada fungsi kognitifnya, hal ini menyebabkan berkurangnya daya ingat serta kemampuan untuk berfikir di usia tua. ${ }^{9,10}$

Namun beberapa hal yang menjadi kelemahan penelitian ini adalah cakupan sampel yang masih terbatas, sebaran sampel yang masih seragam, lamanya minum obat, jenis obat yang kemungkinan berpengaruh pada hasil penelitian, faktor-faktor lain yang dapat mempengaruhi fungsi kognitif pada penderita hipertensi. Sehingga disarakan untuk penelitian selanjutnya dengan jumlah sampel yang lebih banyak, faktor-faktor lain yang dapat mempengaruhi fungsi kognitif pada penderita hipertensi dan cakupan sampel yang lebih luas. 


\section{SIMPULAN}

Berdasarkan hasil studi yang telah dilakukan, maka dapat ditarik kesimpulan terdapat korelasi antara hipertensi dengan terjadinya gangguan kognitif pada lansia di Panti Werdha Wana Seraya Denpasar. Hipertensi mempengaruhi fungsi kognitif pada lansia di Panti Werdha Wana Seraya Denpasar.

\section{DAFTAR PUSTAKA}

1. Dreisbach A. Epidemiology of Hypertension 2013. From http:// emedicine.medscape.com

2. Sharp S, Aarsland D, Day S, Sonnesyn H, Ballard C. Hypertension is a potential risk factor for vascular dementia: systematic review. International Journal of Geriatric Psychiatry. 2011;26:661-669

3. Survei kesehatan nasional. Dalam: kesehatan, editor: Laporan Departemen Kesehatan RI 2004

4. Kaiser Permanente, John Cuddeback. Report From the Panel Members Appointed to the Eighth Joint National Committee (JNC 8). American Medical Association 2013

5. Richard E.Powers, MD. Cerebrovascular Prevention Strategies for Dementia 2006.www.alzbrain.org

6. Harrison D, Guzik T, Love H. Inflamation, Immunity, and Hypertension. Hypertension. 2011;47:132

7. Tonkin A. Atherosclerosis and Hearth Disease: Martin Dunitz 2003
8. Alagiakhrishnan K. 2012. Vascular Dementia 2012. From http:// emedicine.medscape.com

9. Cohen R, Lohr I, Paul R, Boland R.Impairments of Attention and Effort Among Patients With Major Affective Disorders. Neuropsychiatry and Clinical neuroscience. 2001;13:3

10. Seux ML, Thijs L, Forette F, Staessen JA, Birkenhager WH, Bulpitt CJ. Correlates of Cognitive Status of Old Patients with Isolated Systolic Hypertension: the Syst-Eur Vascular Dementia Project. J Hypertens. 2005;16:963-9

11. Ladecola C, Yadeffa, Biller, Bratzke, Sunmin, Seshadri. Impact of Hypertension on Cognitive Function. Hypertension. 2016; 68 (6): e67-e94

12. Obisesan T. Hypertension and cognitive funtion. Clinical Geriatric Medicine. 2009;25:259-88

13. Waldstein S, Katzel. Hypertension and Cognitive Function. Mahwah: NJ: Erlbaum, 2001:15-36

14. Deary I, Pattie A, Whiteman M, Star J, Whalley L. Smoking and Cognitive Change From Age 11 to Age 80. Journal of Neurology, Neurosurgery, and Psychiatry. 2003; 74:1006-1007

15. Lee S, Kawachi I, Berkman L, Grodstein F. Education, Other Socioeconomic Indicators, and Cognitive Function. American Journal of Epidemiology. 2003;157:712-720

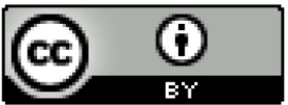

This work is licensed under a Creative Commons Attribution 4.0 International License. 